FINANCIAL: Jurnal Akuntansi

Published by Program Studi Akuntansi STIE Sultan Agung Volume 6-Nomor 2, Desember 2020, (HIm 169-178)

ISSN-P: 2502-4574, ISSN-E: 2686-2581

Available online at: https://financial.ac.id/index.php/financiaI

\title{
RETURN ON ASSET DAN RETURN ON EQUITY DALAM MENILAI PROFITABILITAS PADA PT. PERDANA SATRIA LUWUK BANGGAI
}

\author{
Irwan Moridu ${ }^{1)}$, Nurcahya Hartaty Posumah ${ }^{2)}$ \\ ${ }^{1,2}$ Fakultas Ekonomi Dan Bisnis Universitas Muhammadiyah Luwuk Banggai, Jl. KH. Ahmad Dahlan \\ No. III/79 Luwuk Kab. Banggai Sulawesi Tengah, 94712, Indonesia \\ E-mail : ${ }^{1}$ irwanmoridu@gmail.com, ${ }^{2}$ nurcahyahartatyposumah@gmail.com
}

\begin{abstract}
Abstrak
Tujuan dalam penelitian ini yaitu untuk mengetahui bagaimanakah tingkat profitabilitas pada PT. Perdana Satria Luwuk Banggai dilihat Dari Return On Assets (ROA) Dan Return On Equity (ROE). Jenis data yang digunakan adalah data sekunder, dengan metode pengumpulan data berupa observasi, wawancara, studi pustaka. Metode penelitian yang digunakan adalah deskriptif kuantitatif. Berdasarkan hasil penelitian dan pembahasan yang telah dikemukakan oleh penulis pada bab sebelumnya, maka kesimpulan yang dapat diberikan oleh penulis yaitu selama kurun waktu 2015-2018 pada PT. Perdana Satria Luwuk Banggai, dilihat dari ROA dan ROE mengalami kenaikan yang cukup efektif, dimana nilai dari ROA dan ROE cenderung mengalami peningkatan dimana selisih ROA cukup tinggi dengan rata-rata sebesar $17,93 \%$ dan rata-rata ROE sebesar $24,07 \%$, hal ini menunjukkan bahwa perusahaan efektif dalam menggunakan aktiva dan ekuitasnya sehingga memperoleh sisa hasil usaha yang setiap tahunnya cenderung naik dan efektif.
\end{abstract}

Kata Kunci: ROA, ROE, Profitabilitas

\section{RETURN ON ASSET AND RETURN ON EQUITY IN ASSESSING PROFITABILITY IN PT. PERDANA SATRIA LUWUK BANGGAI}

\begin{abstract}
The purpose of this study is to find out how the level of profitability at PT. Perdana Satria Luwuk Banggai seen from Return On Assets (ROA) and Return On Equity (ROE). The type of data used is secondary data, with data collection methods in the form of observation, interviews, literature study. The research method used is quantitative descriptive. Based on the results of research and discussion that have been raised by the author in the previous chapter, the conclusions that can be given by the author are during the period 2015-2018 at PT. Perdana Satria Luwuk Banggai, seen from the ROA and ROE experienced an increase that is quite effective, where the value of ROA and ROE tends to increase where the difference in ROA is quite high with an average of $17.93 \%$ and an average ROE of $24.07 \%$, p this shows that the company is effective in using its assets and equity so that it gets the remaining results of operations which tend to increase each year and are effective.
\end{abstract}

Keywords: ROA, ROE, Profitability

Article History: Received: 07 Juli 2020 Revised: 14 Okt 2020 Accepted: 26 Okt 2020 


\section{PENDAHULUAN}

Kemampuan suatu perusahaan dalam memperoleh laba dari kegiatan operasional adalah target utama pada kinerja pengelolaan perusahaan, dikarenakan laba yang dihasilkan perusahaan selain merupakan bagian dari kemampuan perusahaan dalam memenuhi kewajiban bagi investornya, juga merupakan bagian dalam membuat nilai suatu perusahaan yang memperlihatkan prospek perusahaan di masa mendatang.

Perencanaan harus disusun sesuai kemampuan dan perkembangan yang dimiliki perusahaan agar pelaksaannya dapat berjalan dengan baik dan lancar. Perkembangan suatu usaha konsolidasi suatu perusahaan dapat dilihat dari data keuangan perusahaan yang didalamnya terdapat berbagai informasi keuangan serta keberhasilan perusahaan yang telah diraih selama periode-periode tertentu.

Sebagai bagian dari cara untuk mengetahui posisi keuangan perusahaan tersebut dapat dilakukan dengan cara analisa laporan keuangan. Informasi yang terdapat dalam laporan keuangan akan membantu berbagai pihak dalam merumuskan atau mempertimbangkan pengambilan keputusan mengenai keuangan.

Laporan keuangan tersebut mampu memberikan makna bagi pihak yang berkepentingan apabila informasi tersebut disandingkan untuk beberapa periode atau lebih dan dianalisis lebih lanjut. Dengan menggunakan laporan keuangan yang disandingkan tersebut termasuk didalamnya data perusbahan yang terjadi dalam kurun waktu tertentu dalam jumlah rupiah dan persentase, maka terdapat beberapa rasio keuangan dalam membantu investor memperoleh hasil analisa laporan keuangan.
Laporan keuangan yang terdiri atas neraca, laporan laba rugi, laporan perubahan ekuitas, catatan atas laporan keuangan, laporan perubahan modal serta laporan arus kas. Bagi manajemen, laporan keuangan sebagai alat pertanggungjawaban kepada pemilik perusahaan, serta menggambarkan tingkat efisiensi operasi dari manajer dalam mengelola perusahaan, yang biasanya dilihat dari besarnya laba yang diperoleh. Bagi pemerintah, laporan keuangan dapat diumumkan sebagai alat untuk keberhasilan kebijakan ekonomi, perpajakan, atau sebagai landasan untuk menetapkan kebijakan baru (Moridu, 2017).

Apabila dalam menghitung rasio keuangan untuk menganalisis neraca akan memperoleh sedikit gambaran kondisi keuangan suatu perusahaan, sedangkan analisis terhadap laporan keuangan laba rugi dapat diperoleh gambaran dari hasil dan pencapaian suatu perusahaan. Laporan keuangan biasanya dipergunakan secara luas apakah itu oleh pengguna intern maupun pengguna ekstern perusahaan.

Pengguna intern adalah pengguna yang membutuhkan beberapa informasi dari analisa laporan keuangan agar dapat membantu mereka di dalam mengelola, merencanakan serta mampu mengendalikan operasional perusahaan. Biasanya pengguna intern adalah manajemen perusahaan, para pengambil keputusan di perusahaan bahkan staf perusahaan.

Sementara keputusan yang diambil oleh pengguna intern akan langsung mempengaruhi operasional perusahaan. Pengguna ekstern merupakan pengguna yang membutuhkan beberapa informasi dari hasil analisa laporan keuangan perusahaan untuk pengambilan keputusan yang menyangkut hubungan mereka dengan perusahaan 
tersebut. Pengguna ekstern seperti investor asing, para kreditor, pemerintah daerah maupun pemerintah pusat serta masyarakat.

PT. Perdana Satria Luwuk Banggai sebagai salah satu pelaku bisnis dalam sistem perekonomian Kabupaten Banggai mempunyai peran, karena PT. Perdana Satria Luwuk Banggai mempunyai fungsi utama yaitu untuk meningkatkan perekonomian di Kabupaten Banggai sebagai penyalur barang-barang yang dibutuhkan masyarakat. Pengembangan usaha sangat diperlukan agar PT. Perdana Satria Luwuk Banggai dapat menempatkan dirinya sebagai suatu bagian ekonomi yang sejajar dengan usahausaha yang bergerak dibidang yang sama lainnya di Kabupaten Banggai.

PT. Perdana Satria Luwuk Banggai sebagai usaha ekonomi yang harus dikembangkan dan diperkuat dalam rangka menumbuhkan keuntungan perusahaan. Profit mempunyai sifat yang cukup sulit untuk ditentukan secara pasti kapan akan tercapai dalam setiap periodenya.

PT. Perdana Satria Luwuk Banggai merupakan usaha yang bergerak dalam distributor barang serba usaha, setiap tahunnya melakukan penyusunan laporan keuangan, dalam penyusunan laporan keuangan PT. Perdana Satria Luwuk Banggai tidak mengetahui rasio keuntungan dari asset dan modal dengan cara menghitung rasio
Return On Assets (ROA) dan Return On Equity (ROE) yang dimiliki sehingga keuntungan PT. Perdana Satria Luwuk Banggai belum terkoordinir dengan baik, ini terlihat dari belum adanya pemahaman dalam menganalisa profitabilitas.

Seperti halnya penelitian yang dilakukan oleh (Sanjaya \& Rizky, 2018) dimana Return On Asset (ROA) cenderung mengalami penurunan, hal ini dikarenankan menurunnya penjualan perusahaan sehingga laba perusahaan juga akan menurun dan nilai ROA dari tahun 2012 sampai 2016 belum memenuhi standar penilaian kementerian BUMN PER10/MBU/2014 dan Return On Equity (ROE) pada tahun 2015 sampai 2016 mengalami penurunan.

Hal ini menunjukkan perusahaan tidak mampu menghasilkan laba atas ekuitas yang dimiliki. Sedangkan penelitian oleh (Winarno, 2017) dengan hasil menunjukkan bahwa kinerja rentabilitas keseluruhan menunjukkan nilai yang baik, kinerja ROA dan ROE selama 2015 dan 2016 belum menunjukkan hasil yang memuaskan hasil karena berada di bawah rata-rata industri. Secara keseluruhan kinerja keuangan perusahaan dapat dikatakan baik

Data yang penulis dapatkan yang berhubungan dengan rasio ROA dan ROE adalah sebagai berikut:

Tabel 1. Laba Usaha, Total Aset dan Ekuitas

\begin{tabular}{|c|c|c|c|}
\hline Tahun & Laba Usaha & Total Asset & Total Ekuitas \\
\hline 2015 & 616.239 .706 & 2.430 .929 .043 & 2.430 .356 .156 \\
\hline 2016 & 446.213 .250 & 2.938 .603 .835 & 1.876 .569 .406 \\
\hline 2017 & 687.403 .292 & 3.685 .583 .962 & 2.563 .583 .962 \\
\hline 2018 & 654.729 .049 & 5.218 .702 .384 & 3.218 .702 .384 \\
\hline
\end{tabular}

Sumber : PT. Perdana Satria Luwuk Banggai (2019)

Data tersebut menunjukkan bahwa laba yang dihasilkan oleh perusahaan mengalami kenaikan yang tidak cukup besar dari kurun waktu 2015 hingga 2018 sedangkan asset perusahaan juga berfluktuasi artinya tahun 2015 mengalami peningkatan 
dan tahun 2018 mengalami peningkatan dan total aktiva mengalami peningkatan yang tidak signifikan, hal inilah yang menjadi permasalahan bahwa laba yang dihasilkan perusahaan tidak maksimal jika dibandingkan dengan asset maupun ekuitas. Dengan latar belakang diatas maka penelitian ini bertujuan untuk menganalisis tingkat profitabilitas pada PT. Perdana Satria Luwuk Banggai dilihat Dari Return On Assets (ROA) dan Return On Equity (ROE).

\section{LANDASAN TEORI}

Pengukuran kinerja didefinisikan sebagai "performing measurement", yaitu kualifikasi dan efisiensi perusahaan atau segmen atau keefektifan dalam pengoperasian bisnis selama periode akuntansi. Dengan demikian pengertian kinerja adalah suatu usaha formal yang dilaksanakan perusahaan untuk mengevaluasi efisien dan efektivitas dari aktivitas perusahaan yang telah dilaksanakan pada periode waktu tertentu (Hanafi, Mamduh M; Halim, 2012).

Rasio profitabilitas menurut (Horne, J.C. dan Wachowicz, 2007) adalah "rasio yang menghubungkan laba dari penjualan dan investasi”. Setiap perusahaan menginginkan tingkat profitabilitas yang tinggi. Untuk dapat melangsungkan hidupnya, perusahaan harus berada dalam keadaan yang menguntungkan (profitable). Penggunaan rasio profitabilitas dapat dilakukan dengan menggunakan perbandingan antara berbagai komponen yang ada di laporan keuangan, terutama laporan keuangan neraca dan laporan laba rugi.
Pengukuran dapat dilakukan untuk beberapa periode operasi. Rasio pengembalian atas total aktiva dikenal dengan nama Return On Asset (ROA). Rasio ini mengukur pengembalian atas total aktiva setelah bunga dan pajak, hasil pengembalian total aktiva atau total investasi menunjukkan kinerja manajemen dalam menggunakan aktiva perusahaan untuk menghasilkan laba.

Return On Assets (ROA) merupakan penilaian profitabilitas atas total assets, dengan cara membandingkan laba setelah pajak dengan rata-rata total aktiva. Return on total assets atau lebih dikenal dengan nama Return on Investment (ROI) merupakan rasio yang menunjukan hasil (return) atas jumlah aktiva yang digunakan dalam perusahaan. Rasio ini juga merupakan suatu ukuran tentang efektivitas manajemen dalam mengelola investasinya. Semakin kecil (rendah) rasio ini, semakin kurang baik, demikian pula sebaliknya (Kasmir, 2014)

Return On Equity (ROE) merupakan rasio yang digunakan untuk mengukur laba bersih setelah pajak dengan modal sendiri. Rasio ini menunjukkan daya untuk menghasilkan laba atas investasi berdasarkan nilai buku para pemegang saham. Menurut (Sutrisno, 2013)"Return on Equity ini sering disebut dengan rate of return on Net Worth yaitu kemampuan perusahaan dalam menghasilkan keuntungan dengan modal sendiri yang dimiliki.

\section{METODE}

Dalam memperoleh data yang relevan dalam penulisan ini, metode pengumpulan dan pengolahan data yang digunakan adalah observasi dan dokumentasi (Sugiyono, 
2012). Metode analisis yang digunakan adalah deskriptif kuantitatif dengan menggunakan rasio profitabilitas, yaitu:

a. Return On Assets (ROA)

Horne (2005:224) menyatakan secara matematis ROA dirumuskan sebagai berikut: $\mathrm{ROA}=\frac{\text { Laba Bersih Setelah Pajak }}{\text { Total Asset }} \times 100 \%$

Semakin tinggi nilai rasio ini maka akan semakin baik, karena asset yang dimiliki perusahaan mampu menghasilkan laba.

b. Return On Equity (ROE)
Horne (2005:225) menyatakan formula untuk menghitung ROE sebagai berikut:

$\mathrm{ROE}=\frac{\text { Laba Bersih Setelah Pajak }}{\text { Total Ekuitas }} \times 100 \%$

Semakin tinggi nilai rasio ini maka akan semakin baik, karena ekuitas yang dimiliki perusahaan mampu menghasilkan laba.

\section{HASIL DAN PEMBAHASAN}

Hasil yang didapatkan dalam penelitian ini berupa laporan keuangan yang berhubungan dengan ROA dan ROE dalam neraca tahun 2015-2018.

Tabel 2. Neraca PT. Perdana Satria Tahun 2015 - 2018

\begin{tabular}{|c|c|c|c|c|}
\hline Keterangan & 2015 (Rp) & $2016(\operatorname{Rp})$ & 2017 (Rp) & 2018 (Rp) \\
\hline Harta Lancar: & & & & \\
\hline Kas dan Bank & 1.430 .929 .043 & 608.048 .522 & 2.198.229.897 & 613.924 .884 \\
\hline Piutang Lain - Lain & 1.000 .000 .000 & 1.700 .000 .000 & 1.000 .000 .000 & 2.000 .000 .000 \\
\hline Persediaan Barang & 0 & 300.000 .000 & 326.000 .000 & \\
\hline Total Harta Lancar & 2.430 .929 .043 & 2.608 .048 .522 & 3.524 .229 .897 & 2.613 .924 .884 \\
\hline Harta Tetap: & & & & \\
\hline Bangunan & 55.000 .000 & 55.000 .000 & 55.000 .000 & 55.000 .000 \\
\hline Kendaraan & 127.000 .000 & 504.777 .500 & 504.777 .500 & 504.777 .500 \\
\hline Inventaris & 5.000 .000 & 5.000 .000 & 5.000 .000 & 45.000 .000 \\
\hline Akumulasi & (187.000.000) & $(234.222 .187)$ & $(403.423 .435)$ & \\
\hline Total Harta Tetap & $\mathbf{0}$ & 330.555.313 & 161.354.065 & 604.777 .500 \\
\hline Total Harta & 2.430.929.043 & 2.938.603.835 & 3.685.583.962 & 5.218 .702 .384 \\
\hline Hutang: & & & & \\
\hline Hutang Usaha & 0 & 1.061 .732 .951 & 1.117 .000 .000 & 2.000 .000 .000 \\
\hline Hutang Pajak & 572.887 & 301.478 .000 & 4.610 .627 & \\
\hline Jumlah Hutang & 572.887 & 1.062.034.429 & 1.121.610.627 & 2.000.000.000 \\
\hline Ekuitas: & & & & \\
\hline Modal & 12.500 .000 & 20.000 .000 & 20.000 .000 & 12.500 .000 \\
\hline Laba Ditahan & 1.801 .616 .450 & 1.410 .356 .156 & 1.856 .569 .406 & 2.551 .473 .335 \\
\hline Laba & & & & \\
\hline Berjalan & 616.239 .706 & 446.213 .250 & 687.403 .929 & 654.729 .049 \\
\hline $\begin{array}{l}\text { Total Hutang Dan } \\
\text { Modal Sendiri }\end{array}$ & 2.430.929.043 & 2.938.603.835 & 3.685.583.962 & 5.218.702.384 \\
\hline
\end{tabular}

Sumber: PT. Perdana Satria (2019) 
Tabel 2 diatas menunjukkan bahwa total harta lancar tahun 2015 hingga 2016 mengalami peningkatan sebesar Rp.2.608.048.522 sedangkan harta tetap, berfluktuasi dimana tahun 2015 adalah Rp.0, 2016 adalah sebesar Rp. 330.555.313. Untuk sisi pasiva hutang tahun 2015 adalah sebesar Rp. $\quad 572.887$ dibandingkan tahun 2016 sebesar Rp. 1.062.034.429. Total harta lancar tahun 2017 hingga 2018 mengalami peningkatan sebesar Rp.2.613.924.884 sedangkan harta tetap, berfluktuasi dimana tahun 2017 adalah Rp.161.354.065, 2018 adalah sebesar Rp. 604.777.500 Untuk sisi pasiva hutang tahun 2017 adalah sebesar Rp. 1.121.610.627dibandingkan tahun 2018 sebesar Rp. 2.000.000.000.

Selanjutnya untuk laporan laba rugi PT. Perdana Satria Luwuk Banggai dari tahun 2015 sampai tahun 2016 disajikan pada tabel dibawah ini:

Tabel 3. Laporan Laba Rugi PT. Perdana Satria Luwuk Banggai Tahun 2015 - 2018

\begin{tabular}{|c|c|c|c|c|}
\hline Keterangan & $\begin{array}{l}2015 \\
(\mathbf{R p})\end{array}$ & $\begin{array}{l}2016 \\
\text { (Rp) }\end{array}$ & $\begin{array}{l}2017 \\
\text { (Rp) }\end{array}$ & $\begin{array}{l}2018 \\
(\mathbf{R p})\end{array}$ \\
\hline $\begin{array}{l}\text { Penerimaan: } \\
\text { Penerimaan }\end{array}$ & & & & \\
\hline $\begin{array}{l}\text { Pengadaan dan } \\
\text { Jasa }\end{array}$ & 5.378 .097 .236 & 3.172 .163 .597 & 4.812 .839 .040 & 6.870 .134 .545 \\
\hline Laba Kotor & 5.378.097.236 & 3.172.163.597 & 4.812 .839 .040 & 6.870 .134 .545 \\
\hline $\begin{array}{l}\text { Biaya-Biaya : } \\
\text { BiayaPokok }\end{array}$ & 4.087 .353 .720 & 2.233 .551 .165 & 3.559 .791 .040 & 5.693 .251 .938 \\
\hline BiayaUmum & 571.528 .116 & 428.654 .432 & 467.144 .000 & 521.983 .000 \\
\hline $\begin{array}{l}\text { Total Beban } \\
\text { Operasional }\end{array}$ & 4.659.178.836 & 2.662.205.597 & 4.026.935.040 & 6.215 .234 .938 \\
\hline Laba Usaha & 719.215.400 & 509.958.000 & 785.904.040 & 654.899.607 \\
\hline $\begin{array}{l}\text { Pendapatan \& } \\
\text { Beban Lain - Lain }\end{array}$ & 0 & 0 & 0 & (170.558) \\
\hline Pajak & 102.975 .694 & 63.744 .750 & 98.500 .071 & - \\
\hline $\begin{array}{l}\text { Laba (Rugi) } \\
\text { Tahun Berjalan }\end{array}$ & 616.239.706 & 446.213 .250 & 687.403.929 & 654.729 .049 \\
\hline
\end{tabular}

Sumber: PT. Perdana Satria Luwuk Banggai (2019)

Dari tabel 3 diatas dapat dilihat bahwa laba tahun 2015 adalah sebesar Rp. 616.239.706,- untuk tahun 2015 adalah sebesar Rp.446.213.250,- sedangkan untuk beban operasional tahun 2015 adalah sebesar Rp.4.659.178.836, tahun 2015 adalah sebesar 
Rp.2.662.205.597,--. Laba tahun 2017 adalah sebesar Rp. 687.403.929,- untuk tahun 2018 adalah sebesar Rp.654.729.049,-- sedangkan untuk beban operasional tahun 2017 adalah sebesar Rp.4.026.935.040, tahun 2018 adalah sebesar Rp.6.215.234.938,-.

Dari data neraca dan laporan laba rugi diatas penulis menghitung ROA dan ROE dari PT. Perdana Satria Luwuk Banggai sebagai berikut:

1. Return On Asset (ROA)

ROA $=\frac{\text { Laba Bersih Setelah Pajak }}{\text { Total Asset }} \times 100 \%$

$2015=\frac{616.239 .706}{2.430 .929 .043} \times 100 \%=25,35 \%$

$$
2016=\frac{446.213 .250}{2.938 .603 .835} \times 100 \%=15,18 \%
$$

$$
\begin{aligned}
& 2017=\frac{687.403 .929}{3.685 .583 .962} \times 100 \%=18,65 \% \\
& 2018=\frac{654.729 .049}{5.218 .702 .384} \times 100 \%=12,54 \%
\end{aligned}
$$

2. Return On Equity (ROE)

$$
\mathrm{ROE}=\frac{\text { Laba Bersih Setelah Pajak }}{\text { Total Ekuitas }} \times 100 \%
$$$$
2015=\frac{616 \cdot 239 \cdot 706}{2 \cdot 430 \cdot 356 \cdot 156} \times 100 \%=25,36 \%
$$$$
2016=\frac{446.213 .250}{1.876 .569 .406} \times 100 \%=23,78 \%
$$$$
2017=\frac{687.403 .929}{2.563 .973 .335} \times 100 \%=26,81 \%
$$$$
2018=\frac{654 \cdot 729 \cdot 049}{3 \cdot 218 \cdot 702 \cdot 384} \times 100 \%=20,34 \%
$$

Tabel 4. ROA dan ROE PT. Perdana Satria Luwuk Banggai Tahun 2015 - 2018

\begin{tabular}{|c|c|c|c|c|c|}
\hline \multirow{2}{*}{ No } & \multicolumn{4}{|c|}{ Tahun } & \multirow{2}{*}{ Capaian } \\
\cline { 2 - 5 } & $\mathbf{2 0 1 5}$ & $\mathbf{2 0 1 6}$ & $\mathbf{2 0 1 7}$ & $\mathbf{2 0 1 8}$ & \\
\hline ROA & $25,35 \%$ & $15,18 \%$ & $18,65 \%$ & $12,54 \%$ & $17,93 \%$ \\
\hline ROE & $25,36 \%$ & $23,78 \%$ & $26,81 \%$ & $20,34 \%$ & $24,07 \%$ \\
\hline
\end{tabular}

Sumber: Data Diolah (2019)

\section{Pembahasan}

Dari tabel 4 diatas dapat dilihat bahwa perkembangan ROA dan ROE selama tahun 2015 hingga tahun 2018 mengalami fluktuasi untuk return on Asset sendiri tahun 2015 adalah 25,35\%, tahun 2016 dan mengalami penurunan menjadi $15,18 \%$ di tahun 2017 mengalami peningkatan sebesar $18,65 \%$, dan tahun 2018 mengalami penurunan menjadi $12,54 \%$. Sedangkan ROE juga mengalami hal yang sama untuk tahun 2015 sebesar $25,36 \%$ mengalami penurunan tahun 2016 yaitu sebesar 23,78\%, tahun 2017mengalami penignkatan menjadi menjadi $26,81 \%$, dan tahun 2018 mengalami penurunan menjadi $20,34 \%$.

Dengan adanya peningkatan ROA dan ROE dari tahun 2015 ke tahun 2018 ini mengindikasikan bahwa PT. Perdana Satria Luwuk Banggai mengelola profitabilitasnya cukup baik karena dari tahun 2015 ke 2018 mengalami peningkatan laba usaha.

ROA merupakan salah satu rasio profitabilitas yang mengukur kemampuan perusahaan dalam menghasilkan laba dari aktiva yang digunakan (Harahap, 2011). ROA yang positif menunjukkan bahwa total aktiva yang dipergunakan untuk beroperasi, perusahaan mampu menghasilkan laba bagi 
perusahaan. Sebaliknya apabila ROA negatif menunjukkan bahwa perusahaan mengalami kerugian (Horne, J.C. dan Wachowicz, 2007). Dalam penelitian ini nilai ROA adalah positif dan cenderung meningkat yang mengindikasikan bahwa perusahaan mengalami pertumbuhan keuangan yang baik.

Diharapkan dalam hasil penelitian ini pengukuran kinerja keuangan menggunakan ROA mampu mengukur secara komprehensif dimana keseluruhannya mempengaruhi laporan keuangan yang tercermin dari rasio ini. Hasil penelitian ini dapat di pergunakan untuk memproyeksikan keuntungan dimasa yang akan datang menggunakan Return On Asset. Asset atau aktiva yang dimiliki oleh PT. Perdana Satria Luwuk Banggai maksudnya adalah keseluruhan harta perusahaan yang dimiliki, yang diperoleh dari modal sendiri maupun dari modal asing yang ikut dalam kegiatan perusahaan yang telah diubah perusahaan menjadi aktiva aktiva perusahaan yang digunakan untuk kelangsungan hidup perusahaan dimasa yang akan datang.

Nilai ROA pada penelitian ini yang semakin meningkat menunjukkan kinerja perusahaan yang semakin baik karena tingkat pengembalian yang semakin besar, dimana ROA yang digunakan untuk mengukur efektivitas keseluruhan dalam menghasilkan laba perusahaan dengan memanfaatkan aktiva yang ada (Sembiring, 2012).

Dengan nilai positif yang dihaslkan dari rasio Return On Asset ini maka perusahaan tersebut berpeluang untuk meningkatkan pertumbuhan modal sendiri, karena rasio ROA ini berhubungan dengan earning atau profitabilitas, dikarenakan apabila nilai Return On Assetsemakin tinggi atau semakin besar dari perusahaan maka semakin baik dan efisienlah pengelolaan aktiva yang dimiliki perusahaan untuk Copyright (C) 2020, FINANCIAL: Jurnal Akuntansi beroperasi sehingga akan meningkatkan keuntungan.(Kasmir, 2010)Karena laba yang besar akan menarik investor atau anggota baru karena perusahaan tersebut memiliki tingkat pengembalian yang semakin tinggi.

Sementara itu ROE yang merupakan jumlah imbal hasil dari laba bersih terhadap ekuitas dan dinyatakan dalam bentuk persen yang mengukur kemampuan perusahaan dalam menghasilkan laba dari modal yang dimilikinya, yang mana dari hasil penelitian ini menyatakan bahwa nilai ROE adalah positif dan cenderung mengalami kenaikan yang berarti semakin efektif perusahaan menggunakan modalnya untuk menghasilkan keuntungan (Nurfadillah, 2011).

Dari hasil penelitian ini menunjukkan nilai ROE yang meningkat memperlihatkan bahwa perusahaan dalam mengelola modal sendiri adalah efektif karena tingkat keuntungan dari investasi yang telah dilakukan oleh pemilik modal sendiri atau dari para investor lainnya.Sedangkan untuk penilaian ROA dan ROE yang dilakukan oleh (Ikhwal, 2016) mendapatkan hasil yang sedikit berbeda. Variabel parsial ROA berpengaruh signifikan terhadap profitabilitas karena nilai $t$-hitung $>t$-tabel yaitu sebesar 3,254>1,667 dengan nilai signifikansi $0,02<0,05$. Variabel ROE memiliki pengaruh negatif signifikan terhadap profitabilitas karena nilai tabel- $t>t$-hitung sebesar $2.250>1,667$ dengan nilai signifikan $0,015<0,05$, dan variabel ROA dan ROE secara bersama-sama mempengaruhi profitabilitas ditunjukkan oleh nilai F-hitung yang lebih besar 5,548>3,191 dengan nilai signifikansi 0,007 . Hasil penelitian tersebut memberikan gambaran bahwa ROA dan ROE dapat memberikan pengaruh baik itu peningkatan maupun penurunan profitabilitas.

Pengukuran ROE ini dapat dikatakan penting dikarenakan para anggota atau 
pemilik perusahaan dapat mengetahui kemampuan perusahaan dalam mengelola modalnya sendiri untuk mendapatkan laba, jika nilai ROE ini negatif akan mengklasifikasikan sebagai usaha atau perusahaan yang kurang baik dalam menghasilkan incomenya. Secara langsung tingkat ROE ini dipengaruhi oleh pendapatan bersih.(K.R. Subramanyam, 2012). Dengan hasil yang positif dan cenderung naik dari tahun 2015 ke 2018 yang menunjukkan hasil ROE yang baik, diharapkan mampu berkembang dan lebih maksimal lagi, yang diharapkan dapat meningkatkan laba di tahun mendatang.

\section{SIMPULAN DAN SARAN}

Berdasarkan hasil penelitian dan pembahasan yang telah dikemukakan oleh penulis pada bab sebelumnya, maka kesimpulan yang dapat diberikan oleh penulis yaitu selama kurun waktu 2015-2018 pada PT. Perdana Satria Luwuk Banggai, dilihat dari ROA dan ROE mengalami kenaikan yang cukup efektif, dimana nilai dari ROA dan ROE cenderung mengalami peningkatan dimana selisih ROA cukup tinggi dengan rata-rata sebesar $17,93 \%$ dan rata-rata ROE sebesar 24,07\%, hal ini menunjukkan bahwa perusahaan efektif dalam menggunakan aktiva dan ekuitasnya sehingga memperoleh sisa hasil usaha yang setiap tahunnya cenderung naik dan efektif.

$$
\text { Saran yang diberikan adalah }
$$
hendaknya manajemen PT. Perdana Satria Luwuk Banggai terus memperhatikan kondisi perusahaan dengan terus efektif dalam mengelola perusahaan, dengan memperhatikan laba usaha dan aktiva yang dimiliki oleh perusahaan dan sebaiknya manajemen PT. Perdana Satria Luwuk Banggai terus meningkatkan tingkat pengembalian atau laba usaha yang Copyright (C) 2020, FINANCIAL: Jurnal Akuntansi didapatkan di tahun yang akan datang dengan memanfaatkan aktiva dan ekuitas yang dimiliki perusahaan guna perkembangan perusahaan kedepannya.

\section{DAFTAR PUSTAKA}

Hanafi, Mamduh M; Halim, A. (2012). Analisis Laporan Keuangan, Edisi Keempat. Yogyakarta: UPP STIM $Y K P N$.

Harahap, S. S. (2011). Teori Akuntansi Edisi Revisi 2011. In Rajawali Pers. https://doi.org/www.rajagrafindo.com

Horne, J.C. dan Wachowicz, J. M. (2007). Prinsip-Prinsip Manajemen Keuangan. In Prinsip-Prinsip Manajemen Keuangan. https://doi.org/10.4324/9781315641348

Ikhwal, N. (2016). ANALISIS ROA DAN ROE TERHADAP PROFITABILITAS BANK DI BURSA EFEK INDONESIA. AL-MASRAF : JURNAL LEMBAGA KEUANGAN DAN PERBANKAN.

K.R. Subramanyam, J. J. W. (2012). Analisis Laporan Keuangan. Edisi Sebelas, Buku Kesatu. In Jakarta: Salemba Empat.

Kasmir. (2010). Kasmir. In PENGANTAR MANAJEMEN KEUANGAN.

Kasmir. (2014). Analisis Laporan Keuangan, Edisi Satu, Cetakan Ketujuh. In Raja Grafindo Persada.

MORIDU, I. (2017). ANALISIS EFISIENSI PENGELOLAAN MODAL KERJA PADA PERUSAHAAN DAERAH AIR MINUM (PDAM) KABUPATEN BANGGAI. Jurnal Ilmiah Manajemen " $E \quad M \quad O \quad R$." https://doi.org/10.32529/emor.v1i2.28

Nurfadillah, M. (2011). Analisis Pengaruh Earning Per Share, Debt to Equity Ratio dan Return on Equity Terhadap Harga Saham PT Unilever Indonesia Tbk. Jurnal Manajemen Dan Akuntansi.

Sanjaya, S., \& Rizky, M. F. (2018). Analisis Profitabilitas Dalam Menilai Kinerja Keuangan Pada PT. Taspen (Persero) Medan.

KITABAH. 
FINANCIAL: Jurnal Akuntansi, Volume 6 Nomor 2, Desember 2020

https://doi.org/.1037//0033-

2909.I26.1.78

Sembiring, H. (2012). Analisis Pengaruh

Karakteristik Perusahaan Terhadap

Kelengkapan Pengungkapan dalam

Laporan Tahunan Perusahaan

Manufaktur yang Terdaftar di Bursa

Efek Indonesia. Jurnal Mediasi.

Sugiyono. (2012). Metode Penelitian

Kuantitatif, Kualitatif dan $\mathrm{R}$ \&

D.Bandung:Alfabeta. Metode Penelitian

Kuantitatif, Kualitatif Dan $R \quad \&$

D.Bandung:Alfabeta.

https://doi.org/10.1017/CBO978110741

5324.004

Sutrisno. (2013). Manajemen Keuangan

Teori Konsep dan Aplikasi. In

Manajemen Keuangan Teori Konsep dan Aplikasi.

Winarno, S. H. (2017). Penilaian Kinerja

Keuangan Perusahaan Melalui Analisis

Rasio Profitabilitas. Jurnal Moneter. 